\title{
UK panel warns of crisis in clinical research careers
}

London. The British government has been urged to set up a major review of academic careers in clinical medicine, in the light of uncertainties about research career prospects for people with medical qualifications resulting from recent reforms in the National Health Service (NHS).

The proposal comes in a report published last week by the House of Lords Select Committee on Science and Technology after a nine-month inquiry into the impact of the reforms on medical research.

The main focus of the report is the difficulties created for research supported by the NHS in the light of the government's introduction of an 'internal market' for the allocation of health resources. It points out that, in principle, the literal application of this philosophy could lead to "the end of curiosity-driven clinical research in the major university hospitals".

In general, however, the report has many complimentary things to say about the measures that have already been introduced to meet this threat. High among these measures was the announcement earlier this year that all forms of research spending by the NHS will be combined into a single, ring-fenced 'funding stream', and the extension of competitive funding for virtually all NHS-supported research projects, as proposed in a report published last year by a panel headed by Tony Culyer, professor of medical economics at the University of York (see Nature 371,275; 1994).

The Lords committee, whose members include a number of prominent former academics, says it feels it should take some of the credit for these moves, for which it has been pushing steadily since the government's reforms were first announced. At the same time, it pinpoints various aspects of the implementation of the Culyer proposals about which it continues to be concerned.

One urgent priority, it says, is to tackle the problem of clinical academic careers. "The evidence that an increasing number of doctors are choosing a career in clinical practice rather than academic medicine is very powerful," says the panel's chairman, Lord Walton of Detchant, formerly dean of medicine at the University of Newcastle.

Factors listed in the report as contributing to this situation include pressure on the funding of academic posts funded by the NHS, the impact of changes in the structure of medical education, uncertainty about whether academic achievements will be taken into account in locally agreed pay-scales, and whether parity will be maintained between NHS consultants and their colleagues in universities.

"We believe that the situation is becom- ing so serious that it requires an investigation in its own rights," says Walton. He says that almost all the evidence submitted to his committee by a wide range of bodies, from university representatives to the British Medical Association, "points in the same direction", but he feels that so far the government "has not taken on board the crisis nature of the situation".

The committee also points out that there is growing concern in medical schools particularly those in London, where the costs of patient care tend to be higher because of research overheads - about the difficulties caused by the financial rules under which local health authorities are now being required to operate.

"We have some evidence that managers in small regional hospitals are becoming reluctant to pay for tertiary refunds to centres of excellence, even with the higher levels of care [the latter] can provide," says Walton. "This is because their costs are high, while the internal market has created an environment in which local hospitals depend for their funding on the number of patients they treat."

More generally, the panel sees threats to the future of biomedical research from the 'bottom-line' mentality, which has inevitably come to dominate much thinking about the allocation of health-care funds allocated to doctors and local health authorities.

"We are concerned about the wall of accounting that has been created between clinicians and scientists, and researchers and administrators," says Walton. His committee expresses particular concern about the disappearance of the 'knock-for-knock' tradition, under which less costly items were shared by health authorities, universities and medical charities, and the increasing extent to which the latter two are being required to take on some of the basic costs associated with research that were formerly covered by the government.

The committee's report has been widely welcomed by both the academic and the biomedical community. Michael Powell, for example, of the Committee of Vice Chancellors and Principals (CVCP) - the body that represents British universities in their collective negotiations with government says that his organization "welcomes all of the panel's recommendations".

Powell says that the CVCP is particularly pleased at the recommendation for an inquiry into clinical academic careers, a topic of increasing concern to university medical schools. But it is keen that this should not be purely an interdepartmental government committee, and should have an independent chairman. David Dickson
European patent filings 1992-94

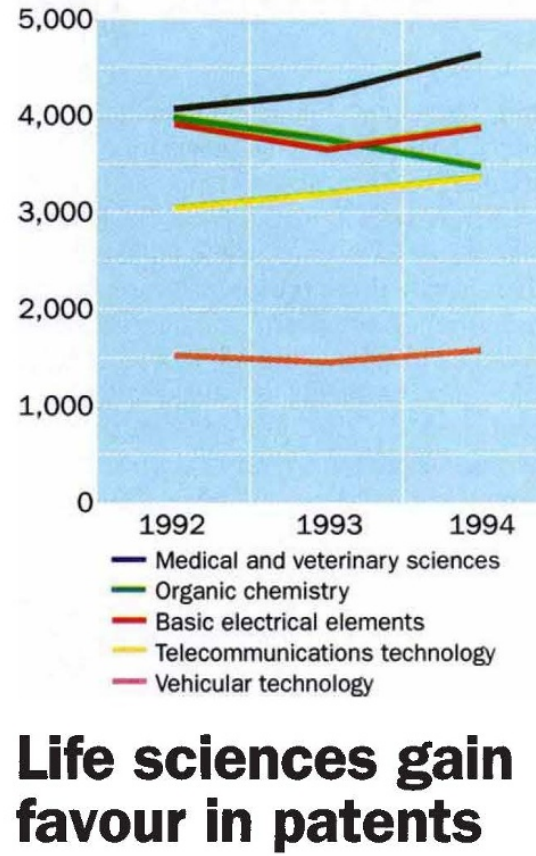

Munich. After a gradual decline over the previous few years in the number of patent applications handled by the European Patent Office (EPO), they increased last year by nearly almost 5 per cent, to a total of 74,000 .

Medical and veterinary technologies attracted the most applications. Indeed, the numbers of applications in this class rose faster than the average in 1994, by 9.5 per cent. Most of this increase came from the United States ( 39 per cent), France ( 22 per cent) and Japan (18 per cent).

In contrast, applications in organic chemistry - the class with the third-largest number of filings - fell significantly. Reduced filings from German, US and Italian companies accounted for most of this decline, which may reflect the switch in interest of the chemical industry from synthetic to biologically derived molecules and processes.

Nearly half of the applications originated in the EPO's 17 member states. Japanese companies were largely responsible for a rise in patent applications in the electrical and electronic industries, including telecommunications. A significant increase in patent applications for vehicle technologies reflected in particular a higher level of filings from German and US companies.

Paul Braendli, president of the EPO, who presented these figures in Munich last week, said that he welcomed the overall increase in the number of applications, but he expressed concern about the continued dominance of non-European applicants in high technology.

Acknowledging that the high cost of patenting through the EPO can put off small European companies (see Nature 375, 270; 1995), he announced that the office will abandon its proposal to increase fees by 3 per cent this year.

Alison Abbott 